\title{
Non-fused ring acceptors for organic solar cells
}

\author{
Mingqun Yang ${ }^{1}$, Wenkui Wei ${ }^{1}$, Xia Zhou ${ }^{1}$, Zhiqiang Wang ${ }^{1}$, Chunhui Duan ${ }^{1,2}$ \\ ${ }^{1}$ Institute of Polymer Optoelectronic Materials and Devices, State Key Laboratory of Luminescent Materials and Devices, South \\ China University of Technology, Guangzhou 510640, Guangdong, China. \\ ${ }^{2}$ State Key Laboratory of Fine Chemicals, Dalian University of Technology, Dalian 116024, Liaoning, China.
}

\begin{abstract}
Correspondence to: Prof. Chunhui Duan, Institute of Polymer Optoelectronic Materials and Devices, State Key Laboratory of Luminescent Materials and Devices, South China University of Technology, No.381 Wushan Road, Guangzhou 510640,

Guangdong, China. E-mail: duanchunhui@scut.edu.cn
\end{abstract}

\begin{abstract}
How to cite this article: Yang M, Wei W, Zhou X, Wang Z, Duan C. Non-fused ring acceptors for organic solar cells. Energy Mater 2021;1:100008. https://dx.doi.org/10.20517/energymater.2021.08
\end{abstract}

Received: 10 Sep 2021 First Decision: 9 Oct 2021 Revised: 18 Oct 2021 Accepted: 20 Oct 2021 Published: 30 Oct 2021

Academic Editors: Yuping Wu, Bin Wang Copy Editor: Xi-Jun Chen Production Editor: Xi-Jun Chen

\begin{abstract}
Organic solar cells (OSCs) have experienced rapid development and achieved significant breakthroughs in power conversion efficiencies owing to the emergence of non-fullerene acceptors (NFAs) with ladder-type multiple fused ring structures. However, the high synthetic complexity and production cost of multiple fused ring NFAs hinder the commercial prospects of OSCs. In this context, the development of non-fused ring acceptors (NFRAs) with simple structures and facile synthesis has been proposed. In this mini review, we summarize the important progress in this field spanning from molecular design strategies to structure-performance relationships. Ultimately, with the aim of realizing the practical application of NFRAs in OSCs, we discuss the current challenges and future directions in terms of achieving high performance and low synthetic complexity simultaneously. These discussions provide valuable insights into the development of new NFRAs.
\end{abstract}

Keywords: Organic solar cells, non-fullerene acceptors, non-fused ring acceptors, low cost, device performance

\section{INTRODUCTION}

Organic solar cells (OSCs) have attracted considerable attention in recent years due to their advantages that include solution processability, lightweight, flexibility and semitransparency ${ }^{[1-6]}$. Generally, OSCs consist of a bulk heterojunction active layer, which employs a p-type polymer as the electron donor and an n-type small molecule as the electron acceptor ${ }^{[7]}$. Over a long period, the electron acceptors become dominated by 
fullerene derivatives ${ }^{[8,9]}$. However, the maximum power conversion efficiency (PCE) of fullerene-based OSCs is limited to $\sim 12 \%{ }^{[10]}$ due to the inherent defects associated with fullerene derivatives, such as a narrow light-absorbing range, low absorption coefficient and nonadjustable energy levels ${ }^{[8,9]}$.

In this context, non-fullerene acceptors (NFAs) that can overcome the drawbacks of fullerene acceptors have emerged. In 2015, Lin et al. ${ }^{[11]}$ reported the first high-performance NFA, ITIC, which features an acceptor-donor-acceptor (A-D-A) structure with a central electron-donating multiple fused ring core and two terminal electron-withdrawing groups. Compared with fullerene-based acceptors, NFAs exhibit obvious advantages, including a broad absorption range, excellent absorption coefficient, tunable energy levels and ordered packing structures ${ }^{[12-14]}$. Generally, the optoelectronic properties and packing structures of NFAs can be regulated by changing the central D and terminal A units ${ }^{[15,16]}$. As a result, NFAs have rapidly led the development of OSCs in recent years ${ }^{[17]}$ and the PCEs of OSCs based on A-D-A-type NFAs have surpassed $16 \%{ }^{[18,19]}$. More encouragingly, Y6, a superior NFA with 2,1,3-benzothiadiazole (BT) as the central electron-deficient core in the A-DA'D-A structure was proposed by Yuan et al. ${ }^{[20]}$ in 2019 , which demonstrated a remarkable PCE of 15.7\% in its first report. Currently, the PCEs of OSCs based on Y6 or its derivatives have exceeded $19 \%$ in single-junction devices ${ }^{[20-33]}$ and tandem devices ${ }^{[34]}$.

As shown in Figure 1A, high-performance NFAs, such as ITIC and Y6, consist of a multiple fused ring framework in their central core. Therefore, they are usually referred to as fused ring acceptors (FRAs). The central fused-ring core in FRAs is multifunctional ${ }^{[12,17,35-39]}$. First, it serves as an electron-donating donor unit to generate the intramolecular charge transfer (ICT) effect and thus extends the absorption range of the resulting FRAs to the near-infrared (NIR) waveband. Second, its coplanar backbone can facilitate the delocalization of $\pi$-electrons, enhance intermolecular $\pi-\pi$ interactions and charge transport. Third, it offers positions for introducing suitable side chains, which provide appropriate solubility and tune the packing structures in the solid state. However, FRAs usually suffer from high synthetic complexity and production costs, thus hampering their large-scale synthesis and limiting the commercialization of OSCs ${ }^{[40-44]}$.

To overcome the drawbacks associated with FRAs, the strategy of using non-fused rings in place of the central fused rings of FRAs was proposed ${ }^{[45]}$. The acceptors generated with this strategy are usually known as non-fused ring acceptors (NFRAs), which possess the advantages of simple structures and facile synthesis. As shown in Figure 1B, the most important structural characteristic of NFRAs is that each unit of the central core is connected by a single bond. The synthetic complexity and production costs of this kind of NFAs can be greatly reduced due to the fact that the single-bond connected structures are much easier to build than fused-ring structures ${ }^{[4,47}$. The absorption spectra, energy levels and molecular packing of NFRAs could be also finely tuned by choosing appropriate building blocks ${ }^{[48-50]}$. Compared with FRAs, NFRAs have more conformational isomers since the single bonds for connecting adjacent units in NFRAs are rotatable, which is harmful to the ordered molecular packing of NFRAs in the solid state ${ }^{[51]}$. This leads to enhanced reorganization energy and hampers charge transport ${ }^{[17,52-54]}$. To solve this problem, noncovalent throughspace intramolecular interactions, including $\mathrm{O} \cdots \mathrm{S}, \mathrm{N} \cdots \mathrm{S}, \mathrm{H} \cdots \mathrm{S}$ and $\mathrm{F} \cdots \mathrm{S}$, were explored to lock the conformation of NFRAs. With these interactions, the rotation of single bonds could be effectively restricted and thus rigid and coplanar structures can also be formed in NFRAs ${ }^{[55-58]}$. As a result, ordered molecular packing in the solid state and efficient electron transport can be realized in NFRAs. So far, the PCEs afforded by NFRAs have exceeded $15 \%{ }^{[59]}$, which are fully comparable to those achieved by A-D-A-type FRAs and are approaching those offered by Y6-derived acceptors.

In this mini review, we summarize the progress of NFRAs in recent years. According to the electronic structure of the building blocks, NFRAs can be classified as A-D-D'-D-A or A-D-A'-D-A-type structures, 


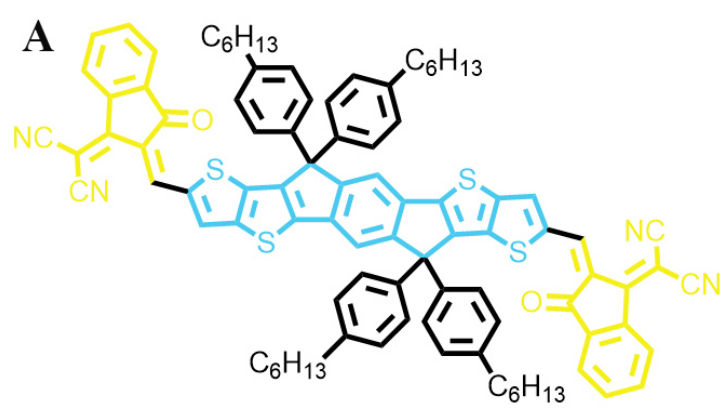

B

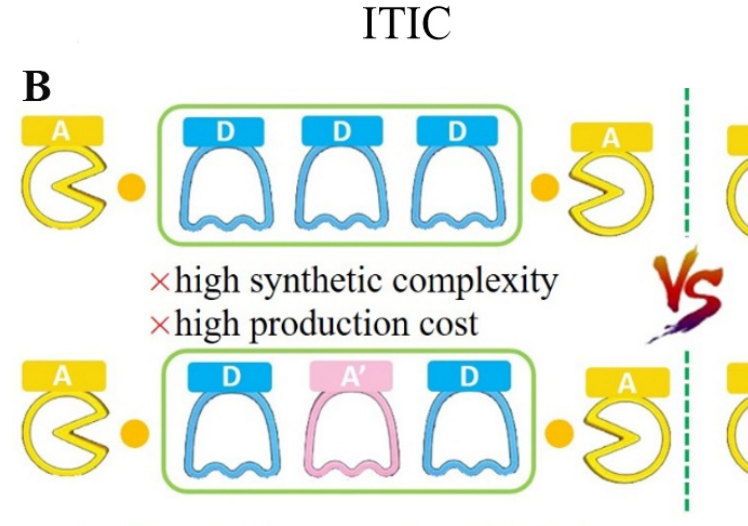

Fused ring acceptors (FRAs)
ITIC

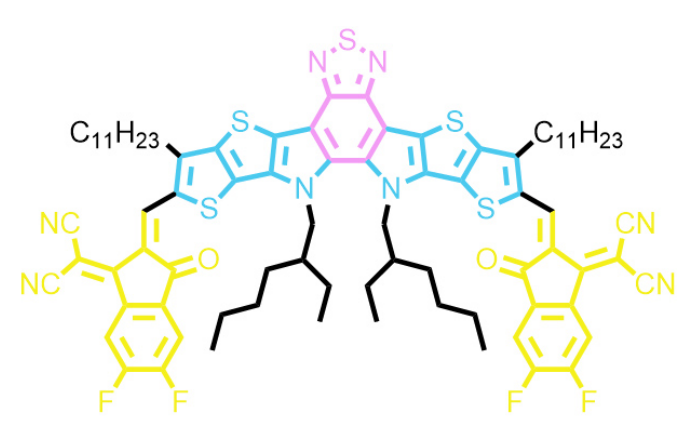

Y6

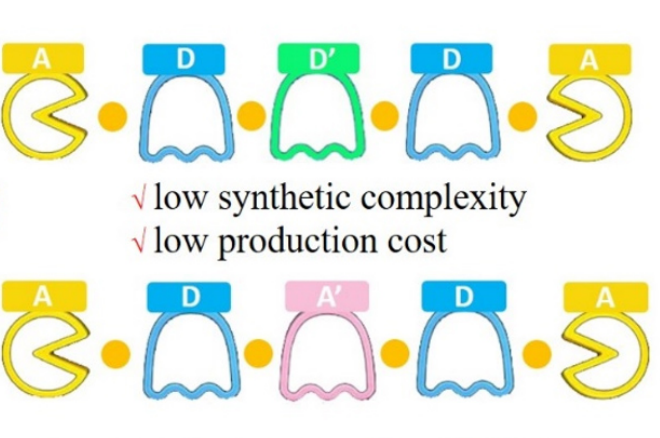

Non-fused ring acceptors (NFRAs)

Figure 1. (A) Representative chemical structures of FRAs with A-D-A (ITIC) and A-DA'D-A (Y6) structure. (B) Comparison between FRAs and NFRAs in structures and characteristics.

where D and A denote electron-donating and electron-accepting units, respectively. Moreover, fully nonfused ring structures have also been developed recently. For each kind of NFRA, the relationships between chemical structure and device performance are discussed. Finally, we discuss the challenges and future directions of NFRAs with the aim of achieving high device performance and low production costs simultaneously.

\section{NFRAS WITH A-D-D'-D-A STRUCTURE}

The chemical structures of representative NFRAs with the A-D-D'-D-A framework are shown in Figure 2. The first NFRA (DF-PCIC) for OSCs was reported by Li et al. ${ }^{[45]}$ and possesses an A-D-D'-D-A structure [Figure $3 \mathrm{~A}$ ]. The central non-fused ring core of DF-PCIC is 2,5-difluorobenzene (DFB, $\mathrm{D}^{\prime}$ ), which is connected to two cyclopentadithiophene (CPDT, D) units by single bonds. The coplanar conformation of DF-PCIC was locked by the F...H noncovalent interaction between the fluorine atoms on DFB and the hydrogen atoms on adjacent CPDT units. Meanwhile, the bulky substituents attached on the $\mathrm{sp}^{3}$ carbon atoms of the CPDT unit can effectively suppress excessive intermolecular aggregation, thus resulting in appropriate phase separation in bulk heterojunction blends. DF-PCIC shows a similar light absorption range [Figure $3 \mathrm{~B}$ ] and energy levels as ITIC but also has obvious advantages in synthesis simplicity. After device optimization based on DF-PCIC:PBDB-T, a remarkable PCE of $10.14 \%$, with a short-circuit current density $\left(J_{\mathrm{SC}}\right)$ of $15.66 \mathrm{~mA} \mathrm{~cm}^{-2}$, an open-circuit voltage $\left(V_{\mathrm{OC}}\right)$ of $0.91 \mathrm{~V}$ and a fill factor $(\mathrm{FF})$ of $72.00 \%$ was obtained. Moreover, the relevant OSCs exhibited excellent morphological and device stability. Notably, the $J_{\mathrm{SC}}$ of the solar cell based on DF-PCIC:PBDB-T was only $15.66 \mathrm{~mA} \mathrm{~cm}{ }^{-2}$, which is much lower than the values obtained by representative FRAs. Generally, the optimal OSCs based on IT-4F and Y 6 can afford $J_{\text {SC }}$ values of $\sim 21$ and $\sim 26 \mathrm{~mA} \mathrm{~cm}^{-2}$, respectively ${ }^{[20]}$. 


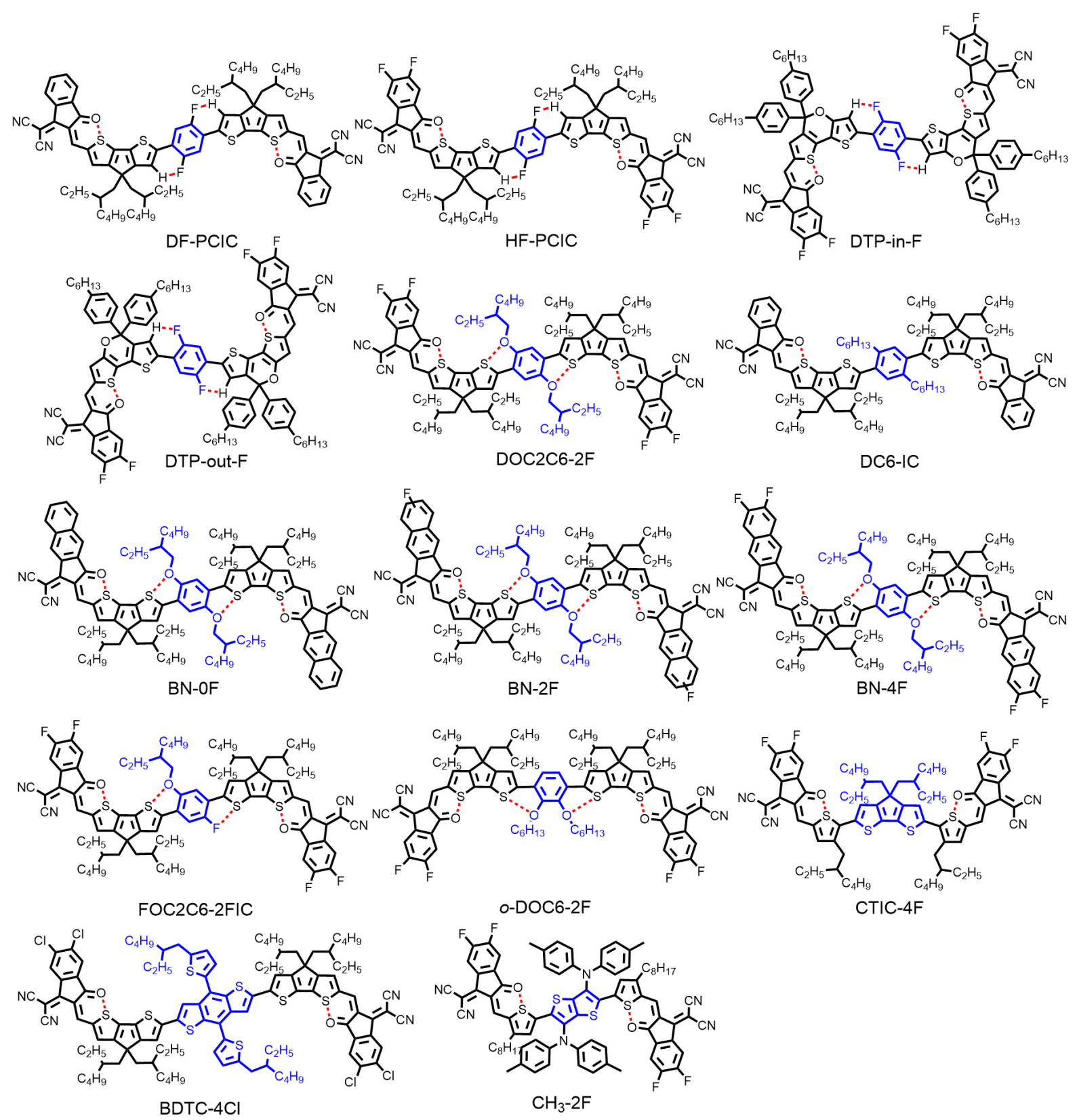

Figure 2. Chemical structures of representative non-fused ring acceptors with A-D-D'-D-A structure.

To overcome the low $J_{\text {SC }}$ of DF-PCIC, a new NFRA (HF-PCIC) with stronger electron-withdrawing end groups was developed by the same group. This new molecule exhibited an obvious bathochromic absorption spectrum owing to the enhanced ICT effect ${ }^{[60]}$. As a result, a higher $J_{\mathrm{SC}}$ of $17.81 \mathrm{~mA} \mathrm{~cm}{ }^{-2}$ and a PCE of $11.49 \%$ were realized for OSCs based on HF-PCIC. Furthermore, 5,5-bis(4-hexylphenyl)-5Hdithieno[3,2-b:2',3'-d]pyran (DTP), which features a stronger electron-donating ability than CPDT was also used to construct NFRAs with the aim of extending the light absorption range ${ }^{[61]}$. Interestingly, the two isomers DTP-out-F and DTP-in-F exhibited similar spectra and energy levels but entirely different stacking orientations in the solid state. Due to the formation of the favorable face-on orientation in DTP-in-F-based donor:acceptor blend films observed from grazing incidence wide-angle X-ray scattering (GIWAXS) patterns [Figure 3C], DTP-in-F offered a higher PCE (10.66\%) than DTP-out-F (3.97\%) in OSCs. 

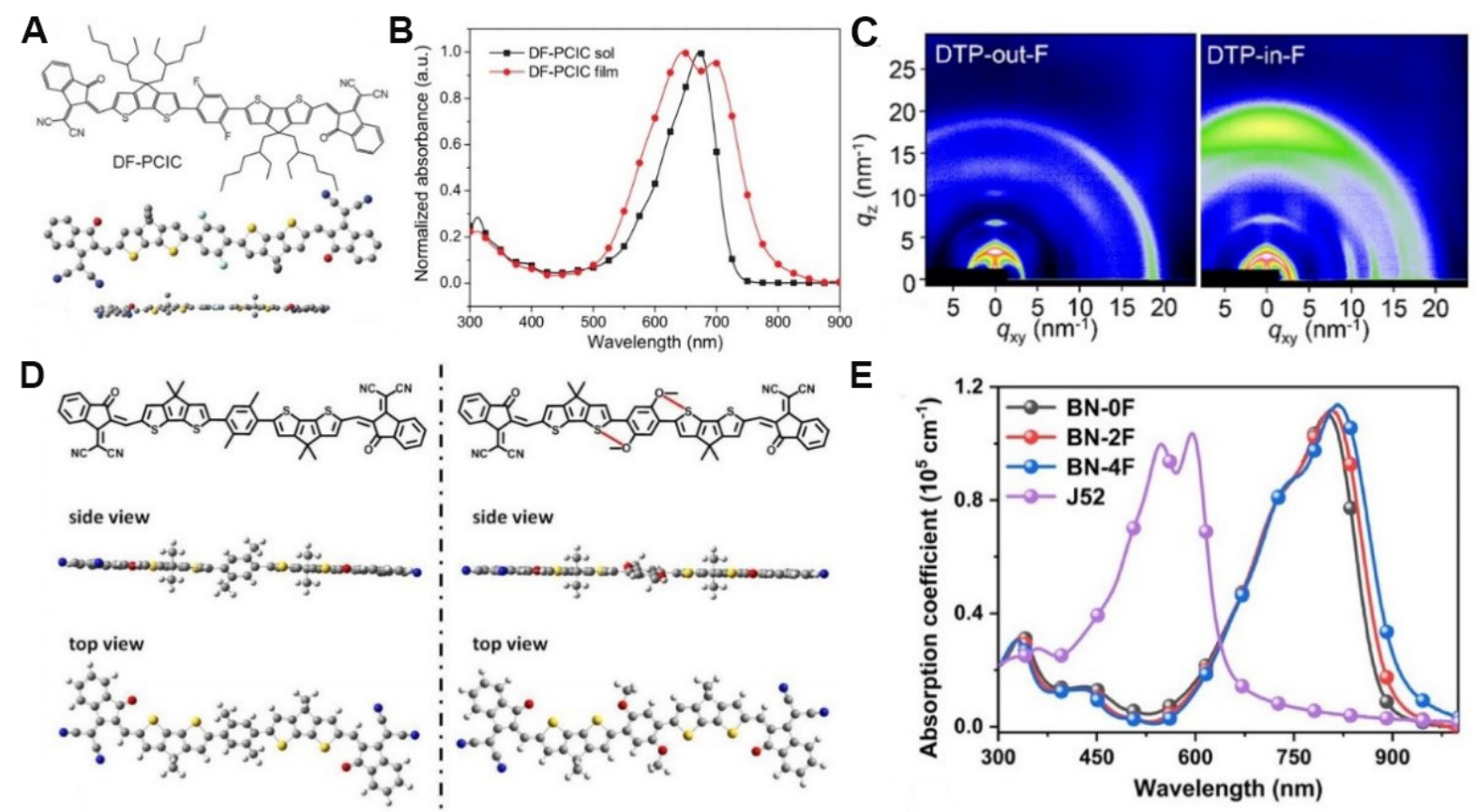

Figure 3. Chemical structure, conformation (A) and absorption spectra (B) of DF-PCIC. (C) Wide-angle X-ray scattering patterns of DTP-out-F and DTP-in-F. (D) Simulated molecular conformation by density functional theory calculations for simplified molecules of DC6-IC and DOC-IC. (E) Absorption spectra of J52 and BN-nF in films. These figures are reproduced with permission from John Wiley and Sons ${ }^{[45,62]}$, the Nature Publishing Group ${ }^{[48]}$ and the American Chemical Society ${ }^{[61]}$, respectively.

Although favorable coplanar conformations of DF-PCIC and HF-PCIC were obtained by the F $\cdots \mathrm{H}$ noncovalent interaction, the $\mathrm{F}$ atoms often reduce the electron-donating ability of the central phenylene unit, thereby resulting in a narrower absorption spectra. Alternatively, Huang et al.$^{[4]}$ developed a set of NFRAs (DOC6-IC, DOC8-IC, DOC2C6-IC, and DOC2C6-2F) by employing the O‥S noncovalent interaction between the central 2,5-bis(alkyloxy)phenylene unit and two flanking CPDT units. These NFRAs all exhibited a favorable coplanar conformation and wide absorption range with an onset approaching $850 \mathrm{~nm}$ in films. Furthermore, the solubility of the NFRAs and the morphology of the blend films could be finely tuned by changing the lateral substituents on the central phenylene unit. Among these NFRAs, DOC2C6-2F offered the highest PCE of $13.24 \%$ associated with a $J_{\mathrm{SC}}$ of $21.35 \mathrm{~mA} \mathrm{~cm}^{-2}$ and a very low non-radiative recombination voltage loss of only $0.27 \mathrm{~V}$. According to density functional theory (DFT) calculations [Figure 3D], the reference molecule DC6-IC without the O...S noncovalent interaction exhibited twisted molecular backbone and thus suffered from imbalanced charge transport and a much poorer PCE (6.87\%). Based on the excellent performance of DOC2C6-2F, Zhang et al. ${ }^{[62]}$ further broadened the absorption range of $\mathrm{DOC} 2 \mathrm{C} 6-2 \mathrm{~F}$ by introducing $\pi$-extended end groups to increase $J_{\mathrm{SC}}$, wherein the degree of multi-fluorination was also finely tuned.

As shown in Figure $3 \mathrm{E}$, all three novel NFRAs (BN-0F, BN-2F and $\mathrm{BN}-4 \mathrm{~F}$ ) exhibited redshifted and extended absorption spectra in films relative to DOC2C6-2F. Among these molecules, the device based on BN-2F:J52 exhibited an outstanding PCE of $14.53 \%$ in lab conditions and a certified PCE of $13.80 \%$ due to the significantly increased $J_{\mathrm{SC}}\left(25.25 \mathrm{~mA} \mathrm{~cm}^{-2}\right)$. This impressive $J_{\mathrm{SC}}$ is close to those of Y6-based highperformance devices, indicating the significant potential of NFRAs. 
Table 1. Device performance of organic solar cells based on representative A-D-D'-D-A-type non-fused ring acceptors

\begin{tabular}{|c|c|c|c|c|c|c|}
\hline Acceptor & Donor & $V_{\text {oc }}(\mathrm{V})$ & $J_{\mathrm{Sc}}\left(\mathrm{mA} \mathrm{cm}{ }^{-2}\right)$ & FF (\%) & PCE (\%) & Ref. \\
\hline DF-PCIC & PBDB-T & 0.91 & 15.66 & 72.00 & 10.14 & [45] \\
\hline HF-PCIC & PBDB-TF & 0.91 & 17.81 & 70.77 & 11.49 & {$[60]$} \\
\hline DTP-in-F & PM6 & 0.91 & 18.54 & 63.20 & 10.66 & {$[61]$} \\
\hline DTP-out-F & PM6 & 0.86 & 10.16 & 45.40 & 3.97 & {$[61]$} \\
\hline DOC2C6-2F & PBDB- $T$ & 0.85 & 21.35 & 73.15 & 13.24 & [48] \\
\hline DC6-IC & PBDB-T & 0.99 & 11.19 & 62.21 & 6.87 & [48] \\
\hline BN-OF & $\mathrm{J} 52$ & 0.84 & 21.91 & 60.10 & 11.00 & [62] \\
\hline $\mathrm{BN}-2 \mathrm{~F}$ & $J 52$ & 0.81 & 25.25 & 70.78 & 14.53 & {$[62]$} \\
\hline $\mathrm{BN}-4 \mathrm{~F}$ & $J 52$ & 0.79 & 25.76 & 64.91 & 13.24 & {$[62]$} \\
\hline $\mathrm{FOC} 2 \mathrm{C} 6-2 \mathrm{FIC}$ & PBDB-T & 0.87 & 19.66 & 72.10 & 12.36 & {$[57]$} \\
\hline $0-\mathrm{DOC} 6-2 \mathrm{~F}$ & PBDB-T & 0.89 & 18.58 & 71.84 & 11.87 & [63] \\
\hline BDTC-4Cl & PBDB- $T$ & 0.86 & 18.56 & 59.50 & 9.54 & [64] \\
\hline CTIC-4F & PCE10 & 0.70 & 23.40 & 64.00 & 10.50 & {$[65]$} \\
\hline $\mathrm{CH}_{3}-2 \mathrm{~F}$ & PBDB-T & 0.77 & 22.76 & 69.85 & 12.28 & {$[66]$} \\
\hline
\end{tabular}

$V_{\text {OC: }}$ Open-circuit voltage; $J_{S C}$ : short-circuit current density; FF: fill factor; PCE: power conversion efficiency.

To date, in addition to the above mentioned building blocks, fluoro-4-alkyloxybenzene (FOC2C6-2FIC ${ }^{[57]}$, 1,2-dialkyloxybenzene $(o-D O C 6-2 \mathrm{~F})^{[63]}$, benzo-[1,2-b:4,5-b']dithiophene (BDTC-4Cl) ${ }^{[64]}$, thiophene (CTIC-4F $)^{[65]}$, thiophene[3,2-b]thiophene $\left(\mathrm{CH}_{3}-2 \mathrm{~F}\right)^{[66]}$ and $\mathrm{IC}-2 \mathrm{Cl}$ have been introduced into NFRAs as electron-donating or electron-withdrawing units. The relevant performance data of the above NFRAs are listed in Table 1.

\section{NFRAS WITH A-D-A'-D-A STRUCTURE}

With the exception of the A-D-D'-D-A-type structure, in light of numerous easily-available electronwithdrawing units, significant attention has been drawn to research into A-D-A'-D-A-type NFRAs featuring electron-withdrawing units as the central core, such as $\mathrm{BT}^{[50,58,67]}$, benzotriazole $(\mathrm{BTz})^{[68-70]}$, benzo- $[1,2-\mathrm{c}: 4,5-$ $\left.\mathrm{c}^{\prime}\right]$ dithiophene-4,8-dione (BDD) $)^{[71,72]}$, benzobis(thiazole) $(\mathrm{BBTz})^{[73]}$, quinoxaline $(\mathrm{Q})^{[74]}$, thieno[3,4-c]pyrrole4,6-dione (TPD) $)^{[71,75]}$, isoindigo (IID) ${ }^{[76]}$ and so on [Figure 4]. Among them, BT and BTz have been widely adopted as A' units to construct NFRAs for their unique merits: (1) quinoidal structures are beneficial for broadening the absorption range; (2) the 5,6-positions of BT and BTz can be readily functionalized; and (3) the N...S noncovalent interaction can be formed between the BT/BTz core and adjacent thiophene rings.

In 2020, Pang et al. ${ }^{[50]}$ reported an A-D-A'-D-A-type NFRA with BT as an $\mathrm{A}^{\prime}$ core (BTCIC-4Cl). The absorption of BTCIC-4Cl was extended to the NIR waveband with an onset of $946 \mathrm{~nm}$ in the solid state, corresponding to an optical band gap $\left(E_{\mathrm{g}}^{\mathrm{opt}}\right)$ of $1.31 \mathrm{eV}$ in terms of the quinoidal character of the BT unit and enhanced ICT effect [Figure 5A]. However, as shown in Figure 5B, the introduction of the BT unit significantly down-shifted the lowest unoccupied molecular orbital (LUMO) energy level of BTCIC-4Cl, which deteriorated the $V_{\mathrm{OC}}$. After device optimization, a moderate photovoltaic performance of BTCIC-4Cl was achieved, with a PCE of $10.50 \%$, a $V_{\text {OC }}$ of $0.75 \mathrm{~V}$ and a $J_{\text {SC }}$ of $21.00 \mathrm{~mA} \mathrm{~cm}$ cm $^{-2}$. Based on the abovementioned results, Wang et al. ${ }^{[58]}$ then systematically investigated the effects of $\mathrm{H}$ (BT-IC4F), F (BT2F-IC4F) and alkoxy chains (BTOR-IC4F) at the 5,6-positions of the BT core on the molecular configuration and device performance. The ladder-like molecular structures locked by the N...S, F ‥S and O...S noncovalent interactions were formed for these acceptors, as suggested by DFT calculations. Compared with BT-IC4F and $\mathrm{BT} 2 \mathrm{~F}-\mathrm{IC} 4 \mathrm{~F}$, the higher molar extinction coefficient, better solubility and elevated LUMO energy level of BTOR-IC4F have endowed more superior performance of OSCs. Consequently, the highest PCE of $11.48 \%$ 

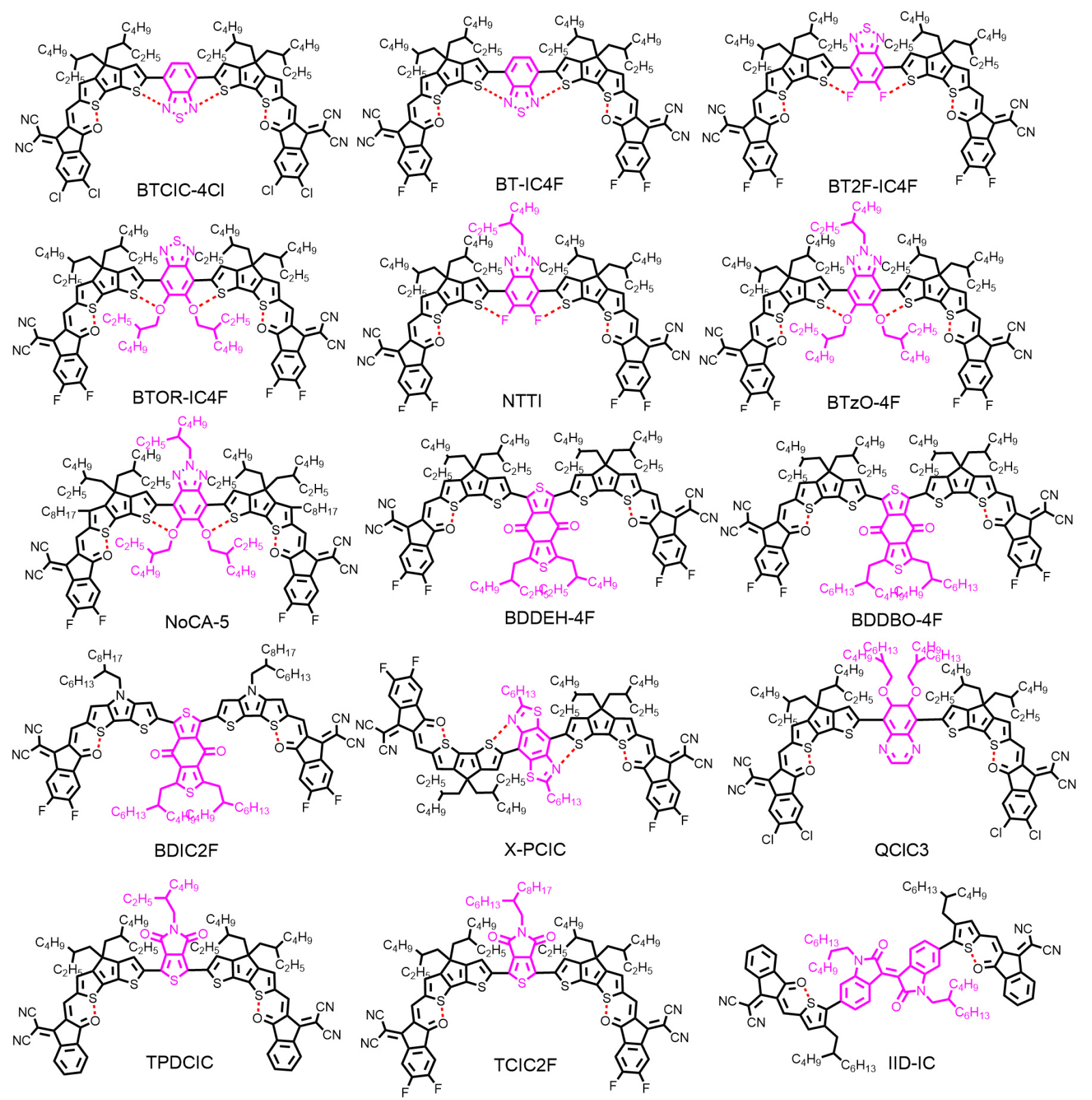

Figure 4. Chemical structures of representative non-fused ring acceptors with A-D-A'-D-A structure.

was achieved for PBDB-T:BTOR-IC4F-based devices, with a $J_{\mathrm{SC}}$ of $20.57 \mathrm{~mA} \mathrm{~cm}^{-2}$ and a $V_{\mathrm{OC}}$ of $0.80 \mathrm{~V}$.

In contrast, BTz with a weaker electron-withdrawing ability is conducive to further increasing the $V_{\mathrm{OC}}{ }^{[77]}$. The first NFRA (NTTI) bearing fluorinated BTz as the A' core was reported by Lv et al. ${ }^{[77]}$. However, due to the insertion of $\mathrm{F}$ atoms, a strong electron-withdrawing element, a similar $V_{\mathrm{OC}}$ compared to BTOR-IC4F was presented ${ }^{[77]}$. Alternatively, with the aim of enhancing the LUMO energy level of NFRAs, a new molecule $(\mathrm{BTzO}-4 \mathrm{~F})$ was reported by Liu et al. ${ }^{[68]}$, which adopted the alkoxy-substituted BTz unit as the A' core. After device optimization, an outstanding PCE of $13.80 \%$ with a high $V_{\text {OC }}$ of $0.84 \mathrm{~V}$ was achieved for the photovoltaic device based on PBDB-T:BTzO-4F, which demonstrates the excellent potential of NFRAs for high-performance OSCs. 

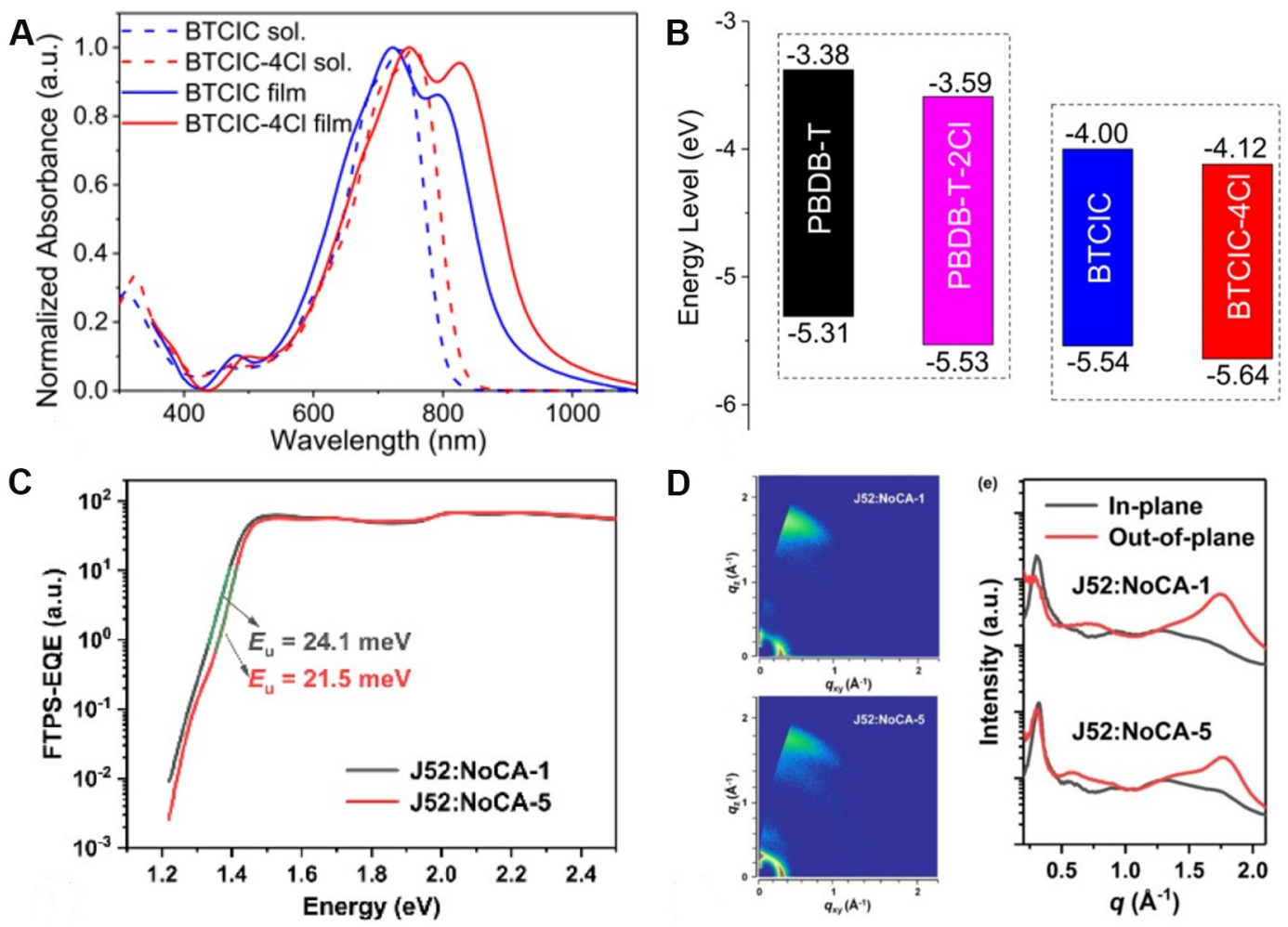

Figure 5. Ultraviolet-vis-NIR absorption spectra (A) and energy levels (B) of BTCIC and BTCIC-4CI. FTPS-EQE (C) and wide-angle Xray scattering patterns (D) of organic solar cells based on J52:NFRAs. These figures are reproduced with permission from the American Chemical Society ${ }^{[50]}$ and John Wiley and Sons ${ }^{[69]}$, respectively.

Later, terminal side chains, referred to the introduction of additional side chains attached to the terminal $\beta$ position of fused-ring cores, were adopted in NFRAs to lock the conformation of end groups, which have been widely applied in high-performance NFAs, especially in Y6 derivatives ${ }^{[20,56,69,78,79]}$. Compared with the counterpart BTzO-4F (herein renamed as NoCA-1), the terminal side chains on NoCA-5 played a significant role in shifting up the LUMO energy level, promoting crystallinity, improving molecular rigidity and reducing the reorganization energy. In particular, the Urbach energy $\left(E_{\mathrm{u}}\right)$ is decreased in the blend of NoCA-5:J52 [Figure 5C], suggesting that the energetic disorder has been effectively reduced in this blend. Moreover, favorable molecular stacking has been formed in the NoCA-5:J52 blend [Figure 5D]. As a result, NoCA-5:J52-based OSCs delivered a remarkable PCE of 14.82\%, whereas the NoCA-1:J52-based devices only gave a PCE of $11.71 \%$.

The BDD unit, possessing a weak electron-withdrawing character, has been widely applied to construct high-performance polymer donors, such as PBDB-T ${ }^{[80]}$ and PM ${ }^{[81]}$. Recently, a set of NFRAs based on the $\mathrm{BDD}$ unit as the central $\mathrm{A}^{\prime}$ core has also been reported. In 2021, two simple electron acceptors, BDDEH-4F and $\mathrm{BDDBO}-4 \mathrm{~F}$, featuring separated BDD units with different side chains as the $\mathrm{A}^{\prime}$ core, were reported by $\mathrm{Wu}$ et al. ${ }^{[82]}$. These molecules were synthesized by a three-step synthesis via direct heteroarylation without any hazardous organostannanes or ligands involved. The devices based on BDDEH-4F:PM6 exhibited a higher PCE of $12.59 \%$ and a larger $J_{\mathrm{SC}}$ of $22.57 \mathrm{~mA} \mathrm{~cm}^{-2}$ due to the more balanced carrier mobilities and suitable phase separation in the active layer compared with that of $\mathrm{BDDBO}-4 \mathrm{~F}$ with longer alkyl side chains (PCE of 9.80\%). Other modifications on BDD-based NFRAs, including replacement of the D units $\left(B_{1 C 2} F\right)$, have also been reported, where similar photovoltaic performance was reported ${ }^{[71,72]}$. A few other electron-deficient building blocks were also used as the central A' units to construct NRFAs [Figure 4], 
which played a unique role in adjusting the absorption, energy level, molecule conformation and active layer morphology ${ }^{[6,71,73-77]}$. The relevant performance data are listed in Table 2.

\section{NFRAS WITH FULLY NON-FUSED STRUCTURES}

Notably, the CPDT unit, serving as the most common D unit in NFRAs, not only possesses outstanding electron-donating ability, but also enables the introduction of bulky substituents for providing sufficient steric hindrance and suppressing excessive intermolecular aggregation. However, the intrinsic fused ring structure of CPDT inevitably raises the production costs of NFRAs. Therefore, NFRAs with fully non-fused structure have emerged [Figure 6]. The first fully non-fused ring acceptor (PTICH) was reported by Yu et al.$^{[83]}$ in 2019, where thiophene, rather than CPDT, was used as the D unit. The same as other NFRAs, the coplanar conformation of PTICH was locked by the O...H noncovalent interaction between the central 2,5-bis(alkyloxy)phenylene unit and flanking thiophene units [Figure 7A]. Furthermore, terminal side chains, including alkyl chains (PTIC) and oxyalkyl chains (PTICO), were adopted to lock the conformation of end groups, which significantly reduced the conformational disorder of the molecules. After device optimization, a PCE of $10.27 \%$ was obtained for the PTIC:PBDB-TF-based devices, representing a new molecule design strategy with a low synthetic complexity index. Moreover, the unique structural features, including the hindered outward-chain and planar $\mathrm{sp}^{3}$ carbon-free backbones of PTIC, played important roles in enhancing the intrinsic photostabilities [Figure $7 \mathrm{~B}$ ] of the molecule, which in turn benefitted the device stability ${ }^{[84]}$.

liu et al. ${ }^{[84]}$ further investigated the device stabilities of A-D-A-type NFAs with fused (IT-4F), non-fused (HF-PCIC) and fully non-fused (PTIC) backbones under continuous one-sun-equivalent irradiation. As shown in Figure 7 C, the PBDB-TF:PTIC-based device maintained $~ 72 \%$ of its initial PCE value for $500 \mathrm{~h}$ of illumination, thereby greatly outperforming the PBDB-TF:IT-4F and PBDB-TF:HF-PCIC-based devices. These results demonstrated that intrinsic photostability and device stability are not limitations to NFRAs. It should be noted that PTIC in neat films exhibited strong molecular stacking, high crystallinity and dominant edge-on orientation from the results of GIWAXS. To optimize the solid stacking and orientation of PTIC, a new NFRA (PTB4Cl) with two-dimensional phenyl chains featuring larger steric hindrance was developed by the same group ${ }^{[s]}$. Compared with PTIC, PTB4Cl exhibited bi-model face-on and edge-on orientations, whereas PTIC exhibited a nearly pure edge-on orientation, showing only an OOP (100) peak. After device optimization, a higher PCE of $12.76 \%$ was obtained for PTB4Cl:PBDB-TF-based devices associated with extended exciton lifetimes and increased charge transfer rates.

Different from the strategy of noncovalent interactions afforded by PTB4Cl, the use of peripheral aromatic substituents with large steric hindrance is also an effective method for constructing the coplanar conformation of fully non-fused ring acceptors. Two novel tetrathiophene-based fully non-fused ring acceptors $(m-4 \mathrm{TBC}-2 \mathrm{~F}$ and $o-4 \mathrm{TBC}-2 \mathrm{~F})$ were reported by Chen et al ${ }^{[49]}$, which feature different substitution positions of alkoxy chains in peripheral phenyl. According to DFT calculations, the huge steric hindrance caused by the alkoxy chains on the peripheral phenyl led to a large dihedral angle $\left(74^{\circ}\right)$ between the molecule backbone and peripheral phenyl, thus resulting in a coplanar backbone of $o-4$ TBC-2F. However, $m-4 \mathrm{TBC}-2 \mathrm{~F}$ with smaller steric hindrance and smaller dihedral angles between the molecule backbone and peripheral phenyl $\left(46^{\circ}\right)$ displayed a much more twisted backbone conformation [Figure $7 \mathrm{D}$ ]. Therefore, the optimized devices based on $o-4 \mathrm{TBC}-2 \mathrm{~F}$ showed a higher PCE of $10.26 \%$ than its counterpart $m-4 \mathrm{TBC}-2 \mathrm{~F}$ ( $2.63 \%)$, benefitting from the higher carrier mobilities, lower energy loss and extended absorption spectra. It is noteworthy that there still existed a dihedral angle above $10^{\circ}$ between the two central thiophene rings for $o-4 \mathrm{TBC}-2 \mathrm{~F}$. 
Table 2. Device performance of organic solar cells based on representative A-D-A'-D-A-type non-fused ring acceptors

\begin{tabular}{|c|c|c|c|c|c|c|}
\hline Acceptor & Donor & $V_{\text {oc }}(\mathbf{V})$ & $J_{\mathrm{sc}}\left(\mathrm{mA} \mathrm{cm}{ }^{-2}\right)$ & FF (\%) & PCE (\%) & Ref. \\
\hline $\mathrm{BTClC}-4 \mathrm{Cl}$ & PBDB-T-2Cl & 0.75 & 21.00 & 66.00 & 10.50 & [50] \\
\hline BT-IC4F & PBDB-T & 0.69 & 21.40 & 66.40 & 9.83 & [58] \\
\hline $\mathrm{BT} 2 \mathrm{~F}-\mathrm{IC} 4 \mathrm{~F}$ & PBDB- $T$ & 0.67 & 19.43 & 64.70 & 8.45 & [58] \\
\hline BTOR-IC4F & PBDB-T & 0.80 & 20.57 & 69.60 & 11.48 & [58] \\
\hline NTTI & PBDB- $T$ & 0.80 & 17.08 & 63.00 & 8.61 & [77] \\
\hline $\mathrm{BTzO}-4 \mathrm{~F}$ & PBDB- $T$ & 0.84 & 23.58 & 69.73 & 13.80 & {$[68]$} \\
\hline NoCA-5 & $\mathrm{J} 52$ & 0.81 & 26.02 & 69.96 & 14.82 & [69] \\
\hline $\mathrm{BDDEH}-4 \mathrm{~F}$ & PM6 & 0.88 & 22.57 & 63.38 & 12.59 & [82] \\
\hline $\mathrm{BDDBO}-4 \mathrm{~F}$ & PM6 & 0.87 & 19.09 & 58.96 & 9.80 & [82] \\
\hline $\mathrm{BDIC} 2 \mathrm{~F}$ & PBDB- $T$ & 0.80 & 9.90 & 37.90 & 3.01 & [71] \\
\hline X-PCIC & PBDB- $T$ & 0.84 & 21.80 & 62.51 & 11.50 & [73] \\
\hline QCIC3 & PBDB-T & 0.82 & 19.39 & 66.90 & 10.55 & {$[74]$} \\
\hline TPDCIC & PBDB-T & 0.83 & 18.16 & 67.14 & 10.12 & [75] \\
\hline $\mathrm{TClC} 2 \mathrm{~F}$ & PBDB- $T$ & 0.71 & 19.10 & 64.60 & 8.80 & [71] \\
\hline IID-IC & J61 & 0.83 & 6.36 & 53.00 & 2.82 & [76] \\
\hline
\end{tabular}

$V_{\text {OC }}$ : Open-circuit voltage; $J_{\text {SC }}$ : short-circuit current density; FF: fill factor; PCE: power conversion efficiency.

Later, Ma et al. ${ }^{[59]}$ found that the dihedral angle could be reduced to $0^{\circ}$ when alkoxyphenyl was replaced by 2,4,6-tri-isopropylphenyl (A4T-16) and 2,4,6-tri-methylphenyl (A4T-23), respectively. The two bulky 2,4,6tri-isopropylphenyl groups have effectively restricted the rotation of the C-C single bond between the two adjacent thiophene rings, thus giving rise to a coplanar central bithiophene core. Moreover, the peripheral 2,4,6-tri-isopropylphenyl is perpendicular to the bithiophene core, which was evidenced by the results from DFT calculations and single-crystal structural analysis [Figure $7 \mathrm{E}$ ]. With the large steric hindrance caused by the 2,4,6-tri-isopropylphenyl group, excessive intermolecular aggregation can be avoided. The singlecrystal analysis also revealed that A4T-16 can form a three-dimensional-interpenetrated network through the close $\pi-\pi$ interaction of its end groups, which facilitates electron transport. As a result, a prominent PCE of $15.20 \%$ and FF of $79.80 \%$ were achieved by A4T-16, which are the highest values for the OSCs based on NFRAs. Notably, NFRAs usually afford inferior FF with respect to FRAs in OSCs ${ }^{[86,87]}$. This drawback might be related to the existence of multiple conformational isomers due to the inevitable rotation of the C-C single bonds in NFRAs, which is harmful to the ordered molecular packing of NFRAs in the solid state ${ }^{[51]}$. The unprecedented FF achieved by Ma et al. ${ }^{[59]}$ provides a promising direction for breaking beyond the FF limitations in NFRA-based OSCs.

In contrast, the solubility and packing structure of tetrathiophene-based fully non-fused ring acceptors were finely tuned by the side-chain engineering on $4 \mathrm{~T}-\mathrm{n}^{[88]}$. Among them, $4 \mathrm{~T}-3$ with four 2-ethylhexyl side chains showed the most suitable crystallinity. The notable PCEs of $10.15 \%$ and $12.04 \%$ were achieved for PBDBT:4T-3 and D18:4T-3-based devices, respectively. Furthermore, compared with other high-efficiency FRAs, such as ITIC-4F, Y6, COisDFIC, 4 TIC- $4 \mathrm{~F}$ and $\mathrm{W} 1$, the representative fully non-fused ring acceptor $4 \mathrm{~T}-3$ exhibited the highest figure-of-merit, which represents the preliminary cost-performance balance point. The relevant performance data of the above NFRAs are listed in Table 3.

\section{CONCLUSION AND OUTLOOK}

Overall, the recent development of NFRAs has been rationally summarized with regards to the relationships between chemical structure and device performance. First, by the incorporation of noncovalent interactions and steric hindrance, the rigid and coplanar structures can be realized in NFRAs, in the results of ordered 


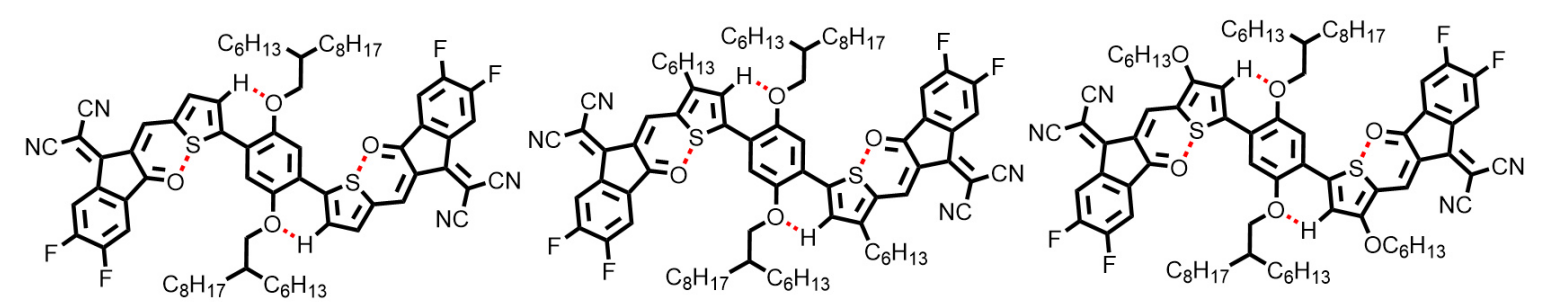

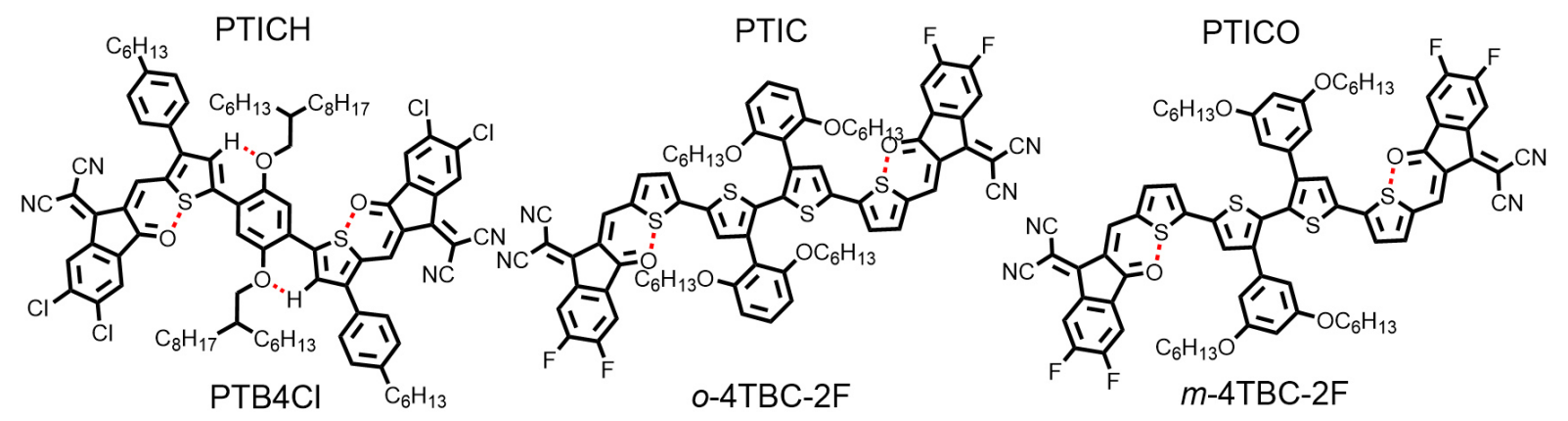

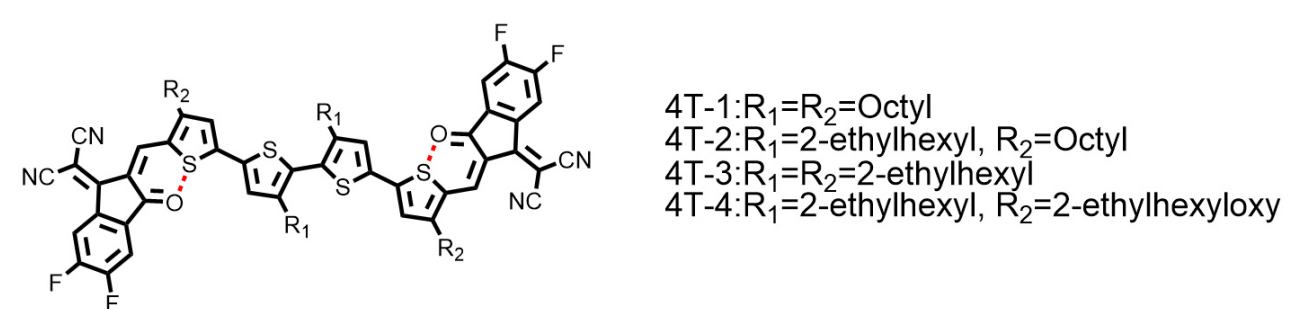

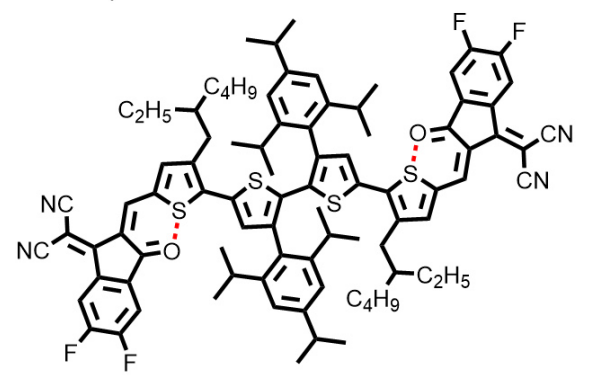

A4T-16

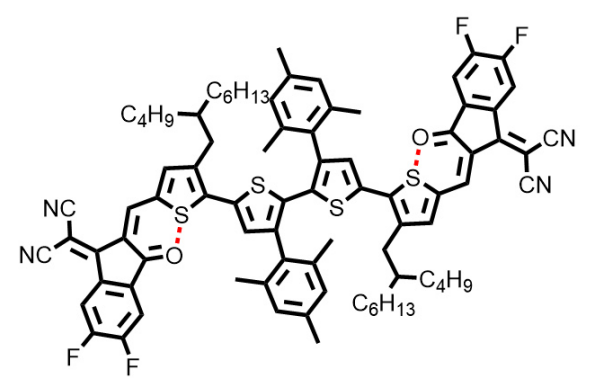

A4T-23

Figure 6. Chemical structures of representative non-fused ring acceptors with fully non-fused structures.

molecular packing and efficient electron transport in the solid state. Second, the chemical structure of NFRAs can be facilely modified based on numerous building blocks. Third, the intrinsic photostability and device stability are not limitations for NFRAs. Moreover, the champion devices based on NFRAs have afforded a remarkable PCE over 15\%, which strongly evidenced the excellent potential of NFRAs for highperformance and cost-effective OSCs. In comparison with FRAs, the development of NFRAs is still in its infancy. To compete with FRAs, the $J_{\mathrm{SC}}$ and FF of the relevant OSCs need to be greatly enhanced. Therefore, additional investigations focusing on the molecular design are essential to further enhance the performance of NFRA-based OSCs. Combined with the unique merits of low costs, simple synthesis and flexibility in structural modification, we believe the breakthrough of high-performance NFRAs will lead to the large-scale commercial applications of OSCs becoming more accessible in the near future. 
Table 3. Device performance of organic solar cells based on representative fully non-fused ring acceptors

\begin{tabular}{|c|c|c|c|c|c|c|}
\hline Acceptor & Donor & $V_{\text {oc }}(V)$ & $J_{\mathrm{Sc}}\left(\mathrm{mA} \mathrm{cm} \mathrm{cm}^{-2}\right)$ & FF (\%) & PCE (\%) & Ref. \\
\hline PTICH & PBDB-TF & 0.92 & 8.22 & 54.00 & 4.08 & [83] \\
\hline PTIC & PBDB-TF & 0.93 & 16.73 & 66.00 & 10.27 & [83] \\
\hline PTICO & PBDB-TF & 1.01 & 12.60 & 52.00 & 6.62 & [83] \\
\hline PTB4Cl & PBDB-TF & 0.93 & 19.01 & 72.17 & 12.76 & [85] \\
\hline $0-4 T B C-2 F$ & PBDB-T & 0.76 & 20.48 & 65.70 & 10.26 & [49] \\
\hline$m-4 T B C-2 F$ & PBDB-T & 0.84 & 7.90 & 40.00 & 2.63 & [49] \\
\hline 4AT-16 & PBDB-TF & 0.88 & 21.80 & 79.80 & 15.20 & [59] \\
\hline 4AT-23 & PBDB-TF & 0.87 & 21.00 & 56.80 & 10.40 & [59] \\
\hline $4 \mathrm{~T}-3$ & PBDB-T & 0.81 & 17.27 & 72.45 & 10.15 & [88] \\
\hline $4 \mathrm{~T}-3$ & D18 & 0.93 & 18.28 & 70.97 & 12.04 & [88] \\
\hline
\end{tabular}

$V_{\text {OC }}$ : Open-circuit voltage; $J_{S C}$ : short-circuit current density; FF: fill factor; PCE: power conversion efficiency.
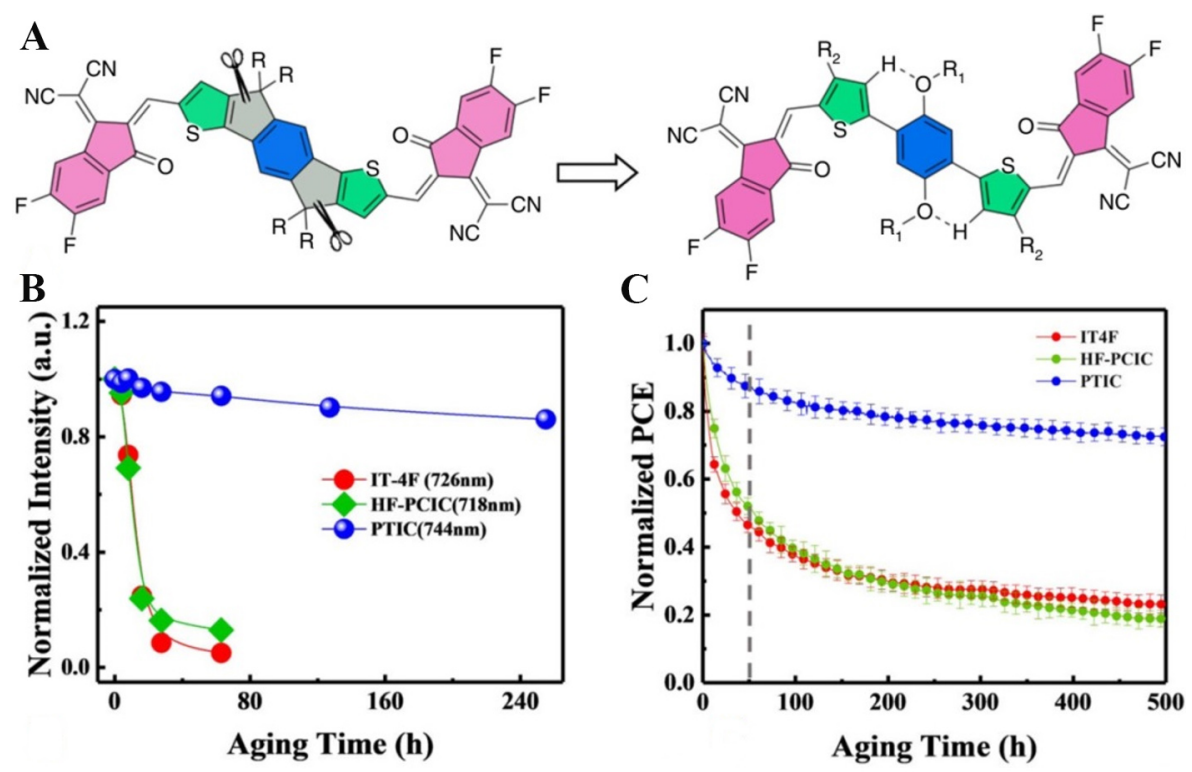

C
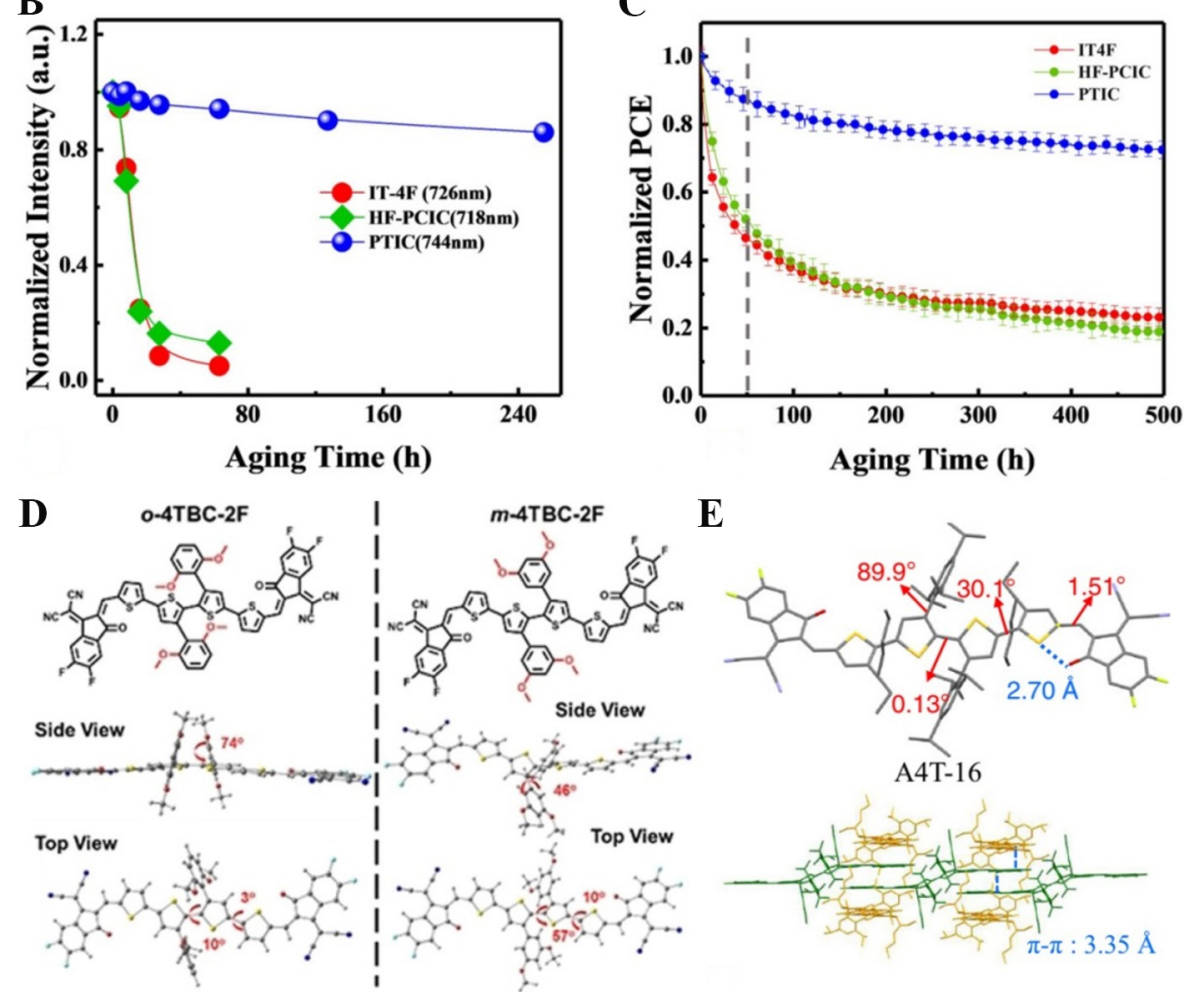

E

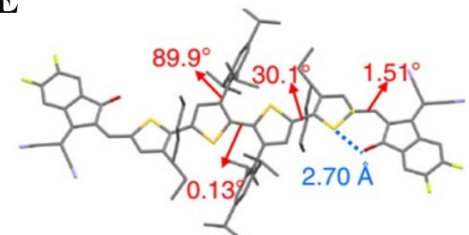

A4T-16

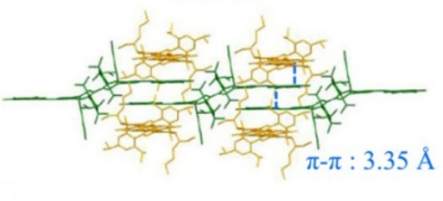

Figure 7. (A) Comparison of chemical structure between fused ring acceptor and fully non-fused acceptors. Change of remaining absorption intensity at $64 \mathrm{~h}$ of irradiation (B) and stabilities of organic solar cells under continuous one-sun-equivalent irradiation (C) of IT-4F, HF-PCIC and PTIC, respectively. (D) Simulated molecular geometries obtained via density functional theory calculations for simplified structures of $0-4$ TBC-2F and $m-4$ TBC-2F. (E) Single-crystal structure and molecular packing model of A4T-16. These figures are reproduced with permission from the Nature Publishing Group ${ }^{[59,83,84]}$ and John Wiley and Sons ${ }^{[85]}$, respectively. 


\section{DECLARATIONS}

\section{Authors' contributions}

Made substantial contributions to conception and design of the study and performed data analysis and interpretation: Yang M, Duan C

Performed data acquisition, as well as proofread manuscript: Wei W, Zhou X, Wang Z

\section{Availability of data and materials}

Not applicable.

\section{Financial support and sponsorship}

This work was supported by the National Key Research and Development Program of China (2017YFA0206600 and 2019YFA0705900), National Natural Science Foundation of China (21875072 and U20A6002), Guangdong Innovative an Entrepreneurial Research Team Program (2019ZTo8L075), and Open Funds of State Key Laboratory of Fine Chemicals (KF1901).

\section{Conflicts of interest}

All authors declared that there are no conflicts of interest.

\section{Ethical approval and consent to participate}

Not applicable.

\section{Consent for publication}

Not applicable.

\section{Copyright}

(c) The Author(s) 2021.

\section{REFERENCES}

1. Yu G, Gao J, Hummelen JC, Wudl F, Heeger AJ. Polymer photovoltaic cells: enhanced efficiencies via a network of internal donoracceptor heterojunctions. Science 1995;270:270-91. DOI

2. Inganäs O. Organic photovoltaics over three decades. Adv Mater 2018;30:e1800388. DOI PubMed

3. Hou J, Inganäs O, Friend RH, Gao F. Organic solar cells based on non-fullerene acceptors. Nat Mater 2018;17:119-28. DOI PubMed

4. Brus VV, Lee J, Luginbuhl BR, Ko SJ, Bazan GC, Nguyen TQ. Solution-processed semitransparent organic photovoltaics: from molecular design to device performance. Adv Mater 2019;31:e1900904. DOI PubMed

5. Fukuda K, Yu K, Someya T. The future of flexible organic solar cells. Adv Energy Mater 2020;10:2000765. DOI

6. Zhang Y, Duan C, Ding L. Indoor organic photovoltaics. Science Bulletin 2020;65:2040-2. DOI

7. Lu L, Zheng T, Wu Q, Schneider AM, Zhao D, Yu L. Recent advances in bulk heterojunction polymer solar cells. Chem Rev 2015;115:12666-731. DOI PubMed

8. Yue Q, Liu W, Zhu X. n-Type molecular photovoltaic materials: design strategies and device applications. J Am Chem Soc 2020;142:11613-28. DOI PubMed

9. Lai Y, Cheng Y, Hsu C. Applications of functional fullerene materials in polymer solar cells. Energy Environ Sci 2014; 7:1866. DOI

10. Kumari T, Lee SM, Kang S, Chen S, Yang C. Ternary solar cells with a mixed face-on and edge-on orientation enable an unprecedented efficiency of 12.1\%. Energy Environ Sci 2017;10:258-65. DOI

11. Lin Y, Wang J, Zhang ZG, et al. An electron acceptor challenging fullerenes for efficient polymer solar cells. Adv Mater 2015;27:1170-4. DOI PubMed

12. Wang J, Zhan X. Fused-ring electron acceptors for photovoltaics and beyond. Acc Chem Res 2021;54:132-43. DOI PubMed

13. Zhang J, Tan HS, Guo X, Facchetti A, Yan H. Material insights and challenges for non-fullerene organic solar cells based on small molecular acceptors. Nat Energy 2018;3:720-31. DOI

14. Cheng P, Li G, Zhan X, Yang Y. Next-generation organic photovoltaics based on non-fullerene acceptors. Nature Photon 2018;12:131-42. DOI

15. Yao H, Cui Y, Yu R, Gao B, Zhang H, Hou J. Design, synthesis, and photovoltaic characterization of a small molecular acceptor with an ultra-narrow band gap. Angew Chem Int Ed Engl 2017;56:3045-9. DOI PubMed

16. Shi X, Chen J, Gao K, et al. Terthieno[3,2-b]thiophene (6T) based low bandgap fused-ring electron acceptor for highly efficient solar cells with a high short-circuit current density and low open-circuit voltage loss. Adv Energy Mater 2018;8:1702831. DOI 
17. Yan C, Barlow S, Wang Z, et al. Non-fullerene acceptors for organic solar cells. Nat Rev Mater 2018;3:18003. DOI

18. Tang C, Ma X, Wang JY, et al. High-performance ladder-type heteroheptacene-based nonfullerene acceptors enabled by asymmetric cores with enhanced noncovalent intramolecular interactions. Angew Chem Int Ed Engl 2021;60:19314-23. DOI

19. Ma Y, Zhang M, Wan S, et al. Efficient organic solar cells from molecular orientation control of m-series acceptors. Joule 2021;5:197209. DOI

20. Yuan J, Zhang Y, Zhou L, et al. Single-junction organic solar cell with over 15\% efficiency using fused-ring acceptor with electrondeficient core. Joule 2019;3:1140-51. DOI

21. Zhu C, Yuan J, Cai F, et al. Tuning the electron-deficient core of a non-fullerene acceptor to achieve over $17 \%$ efficiency in a singlejunction organic solar cell. Energy Environ Sci 2020;13:2459-66. DOI

22. Cui Y, Yao H, Zhang J, et al. Single-junction organic photovoltaic cells with approaching $18 \%$ efficiency. Adv Mater 2020;32:e1908205. DOI PubMed

23. Liu Q, Jiang Y, Jin K, et al. 18\% efficiency organic solar cells. Science Bulletin 2020;65:272-5. DOI

24. Chen S, Feng L, Jia T, et al. High-performance polymer solar cells with efficiency over $18 \%$ enabled by asymmetric side chain engineering of non-fullerene acceptors. Sci China Chem 2021;64:1192-9. DOI

25. Bi P, Zhang S, Chen Z, et al. Reduced non-radiative charge recombination enables organic photovoltaic cell approaching $19 \%$ efficiency. Joule 2021;5:2408-19. DOI

26. Meng H, Liao C, Deng M, Xu X, Yu L, Peng Q. $18.77 \%$ efficiency organic solar cells promoted by aqueous solution processed cobalt(II) acetate hole transporting layer. Angew Chem Int Ed Engl 2021;60:22554-61. DOI PubMed

27. Cui Y, Xu Y, Yao H, et al. Single-junction organic photovoltaic cell with 19\% efficiency. Adv Mater 2021;33:e2102420. DOI PubMed

28. Li C, Zhou J, Song J, et al. Non-fullerene acceptors with branched side chains and improved molecular packing to exceed $18 \%$ efficiency in organic solar cells. Nat Energy 2021;6:605-13. DOI

29. Zhan L, Li S, Xia X, et al. Layer-by-layer processed ternary organic photovoltaics with efficiency over 18. Adv Mater 2021;33:e2007231. DOI PubMed

30. Qin J, Zhang L, Zuo C, et al. A chlorinated copolymer donor demonstrates a $18.13 \%$ power conversion efficiency. J Semicond 2021;42:010501. DOI

31. Jin K, Xiao Z, Ding L. D18, an eximious solar polymer! J Semicond 2021;42:010502. DOI

32. Li X, Xu J, Xiao Z, Wang X, Zhang B, Ding L. Dithieno[3',2':3,4;2",3":5,6]benzo[1,2-c][1,2,5]oxadiazole-based polymer donors with deep HOMO levels. J Semicond 2021;42:060501. DOI

33. Meng X, Jin K, Xiao Z, Ding L. Side chain engineering on D18 polymers yields $18.74 \%$ power conversion efficiency. J Semicond 2021;42:100501. DOI

34. Wang J, Zheng Z, Zu Y, et al. A tandem organic photovoltaic cell with $19.6 \%$ efficiency enabled by light distribution control. Adv Mater 2021;33:e2102787. DOI PubMed

35. Wang H, Cao J, Yu J, et al. Molecular engineering of central fused-ring cores of non-fullerene acceptors for high-efficiency organic solar cells. J Mater Chem A 2019;7:4313-33. DOI

36. Duan C, Ding L. The new era for organic solar cells: non-fullerene small molecular acceptors. Science Bulletin 2020;65:1231-3. DOI

37. Dey S. Recent progress in molecular design of fused ring electron acceptors for organic solar cells. Small 2019;15:e1900134. DOI PubMed

38. Xu YX, Chueh CC, Yip HL, et al. Improved charge transport and absorption coefficient in indacenodithieno[3,2-b]thiophene-based ladder-type polymer leading to highly efficient polymer solar cells. Adv Mater 2012;24:6356-61. DOI PubMed

39. Shen F, Xu J, Li X, Zhan C. Nonfullerene small-molecule acceptors with perpendicular side-chains for fullerene-free solar cells. $J$ Mater Chem A 2018;6:15433-55. DOI

40. Yang X, Ding L. Organic semiconductors: commercialization and market. $J$ Semicond 2021;42:090201. DOI

41. Osedach TP, Andrew TL, Bulović V. Effect of synthetic accessibility on the commercial viability of organic photovoltaics. Energy Environ Sci 2013;6:711. DOI

42. Li N, Mcculloch I, Brabec CJ. Analyzing the efficiency, stability and cost potential for fullerene-free organic photovoltaics in one figure of merit. Energy Environ Sci 2013;11:1355-61. DOI

43. Yang W, Wang W, Wang Y, et al. Balancing the efficiency, stability, and cost potential for organic solar cells via a new figure of merit. Joule 2021;5:1209-30. DOI

44. Li X, Pan F, Sun C, et al. Simplified synthetic routes for low cost and high photovoltaic performance n-type organic semiconductor acceptors. Nat Commun 2019;10:519. DOI PubMed PMC

45. Li S, Zhan L, Liu F, et al. An unfused-core-based nonfullerene acceptor enables high-efficiency organic solar cells with excellent morphological stability at high temperatures. Adv Mater 2018;30:1705208. DOI PubMed

46. Peng W, Zhang G, Shao L, et al. Simple-structured small molecule acceptors constructed by a weakly electron-deficient thiazolothiazole core for high-efficiency non-fullerene organic solar cells. J Mater Chem A 2018;6:24267-76. DOI

47. Wang K, Lv J, Duan T, et al. Simple near-infrared nonfullerene acceptors enable organic solar cells with $>9 \%$ efficiency. ACS Appl Mater Interfaces 2019;11:6717-23. DOI PubMed

48. Huang H, Guo Q, Feng S, et al. Noncovalently fused-ring electron acceptors with near-infrared absorption for high-performance organic solar cells. Nat Commun 2019;10:3038. DOI PubMed PMC

49. Chen YN, Li M, Wang Y, et al. A fully non-fused ring acceptor with planar backbone and near-IR absorption for high performance polymer solar cells. Angew Chem Int Ed Engl 2020;59:22714-20. DOI PubMed 
50. Pang S, Zhou X, Zhang S, et al. Nonfused nonfullerene acceptors with an A-D-A'-D-A framework and a benzothiadiazole core for high-performance organic solar cells. ACS Appl Mater Interfaces 2020;12:16531-40. DOI PubMed

51. Liu Y, Zhang Z, Feng S, et al. Exploiting noncovalently conformational locking as a design strategy for high performance fused-ring electron acceptor used in polymer solar cells. J Am Chem Soc 2017;139:3356-9. DOI PubMed

52. Fei Z, Eisner FD, Jiao X, et al. An alkylated indacenodithieno[3,2-b]thiophene-based nonfullerene acceptor with high crystallinity exhibiting single junction solar cell efficiencies greater than 13\% with low voltage losses. Adv Mater 2018;30:1705209. DOI

53. Yao H, Chen Y, Qin Y, et al. Design and synthesis of a low bandgap small molecule acceptor for efficient polymer solar cells. $A d v$ Mater 2016;28:8283-7. DOI PubMed

54. Huang C, Liao X, Gao K, et al. Highly efficient organic solar cells based on S,N-heteroacene non-fullerene acceptors. Chem Mater 2018;30:5429-34. DOI

55. Huang H, Yang L, Facchetti A, Marks TJ. Organic and polymeric semiconductors enhanced by noncovalent conformational locks. Chem Rev 2017;117:10291-318. DOI PubMed

56. Zhang Z, Yu J, Yin X, et al. Conformation locking on fused-ring electron acceptor for high-performance nonfullerene organic solar cells. Adv Funct Mater 2018;28:1705095. DOI

57. Feng S, Li M, Tang N, et al. Regulating the packing of non-fullerene acceptors via multiple noncovalent interactions for enhancing the performance of organic solar cells. ACS Appl Mater Interfaces 2020;12:4638-48. DOI PubMed

58. Wang Y, Liu Z, Cui X, et al. Small molecule acceptors with a ladder-like core for high-performance organic solar cells with low nonradiative energy losses. $J$ Mater Chem A 2020;8:12495-501. DOI

59. Ma L, Zhang S, Zhu J, et al. Completely non-fused electron acceptor with 3D-interpenetrated crystalline structure enables efficient and stable organic solar cell. Nat Commun 2021;12:5093. DOI PubMed PMC

60. Li S, Zhan L, Zhao W, et al. Revealing the effects of molecular packing on the performances of polymer solar cells based on A-D-CD-A type non-fullerene acceptors. J Mater Chem A 2018;6:12132-41. DOI

61. Zhao J, Xu X, Yu L, Li R, Li Y, Peng Q. Highly efficient non-fused-ring electron acceptors enabled by the conformational lock and structural isomerization effects. ACS Appl Mater Interfaces 2021;13:25214-23. DOI PubMed

62. Zhang X, Qin L, Yu J, et al. High-performance noncovalently fused-ring electron acceptors for organic solar cells enabled by noncovalent intramolecular interactions and end-group engineering. Angew Chem Int Ed Engl 2021;60:12475-81. DOI PubMed

63. Hou R, Li M, Ma X, et al. Noncovalently fused-ring electron acceptors with $\mathrm{C}_{2 \mathrm{v}}$ symmetry for regulating the morphology of organic solar cells. ACS Appl Mater Interfaces 2020;12:46220-30. DOI PubMed

64. Yi Y, Feng H, Zheng N, et al. Small molecule acceptors with a nonfused architecture for high-performance organic photovoltaics. Chem Mater 2019;31:904-11. DOI

65. Lee J, Ko S, Lee H, et al. Side-chain engineering of nonfullerene acceptors for near-infrared organic photodetectors and photovoltaics. ACS Energy Lett 2019;4:1401-9. DOI

66. Wang $\mathrm{X}, \mathrm{Lu} \mathrm{H}$, Zhou J, et al. High-performance simple nonfused ring electron acceptors with diphenylamino flanking groups. ACS Appl Mater Interfaces 2021;13:39652-9. DOI PubMed

67. Yu H, Qi Z, Li X, et al. Modulating energy level on an A-D-A'-D-A-type unfused acceptor by a benzothiadiazole core enables organic solar cells with simple procedure and high performance. Sol RRL 2020;4:2000421. DOI

68. Liu X, Wei Y, Zhang X, Qin L, Wei Z, Huang H. An A-D-A'-D-A type unfused nonfullerene acceptor for organic solar cells with approaching 14\% efficiency. Sci China Chem 2021;64:228-31. DOI

69. Zhang X, Li C, Qin L, et al. Side-chain engineering for enhancing the molecular rigidity and photovoltaic performance of noncovalently fused-ring electron acceptors. Angew Chem Int Ed Engl 2021;60:17720-5. DOI PubMed

70. Huang J, Gao C, Fan X, Zhu X, Yang L. A-D-C-D-A type non-fullerene acceptors based on the benzotriazole (BTA) unfused core for organic solar cells. New J Chem 2021;45:12802-7. DOI

71. $\mathrm{Li} \mathrm{Y,} \mathrm{Fu} \mathrm{H,} \mathrm{Wu} \mathrm{Z,} \mathrm{et} \mathrm{al.} \mathrm{Regulating} \mathrm{the} \mathrm{aggregation} \mathrm{of} \mathrm{unfused} \mathrm{non-fullerene} \mathrm{acceptors} \mathrm{via} \mathrm{molecular} \mathrm{engineering} \mathrm{towards} \mathrm{efficient}$ polymer solar cells. ChemSusChem 2021;14:3579-89. DOI PubMed

72. Luo D, Lai X, Zheng N, et al. High-performance and low-energy loss organic solar cells with non-fused ring acceptor by alkyl chain engineering. Chemical Engineering Journal 2021;420:129768. DOI

73. Li S, Zhan L, Lau T, et al. Near-infrared nonfullerene acceptors based on benzobis(thiazole) unit for efficient organic solar cells with low energy loss. Small Methods 2019;3:1900531. DOI

74. Ye S, Chen S, Li S, et al. Synergistic effects of chlorination and branched alkyl side chain on the photovoltaic properties of simple non-fullerene acceptors with quinoxaline as the core. ChemSusChem 2021;14:3599-606. DOI PubMed

75. Geng S, Yang W, Gao J, et al. Non-fullerene acceptors with a thieno[3,4-c]pyrrole-4,6-dione (TPD) core for efficient organic solar cells. Chin J Polym Sci 2019;37:1005-14. DOI

76. Miao J, Meng B, Liu J, Wang L. An A-D-A'-D-A type small molecule acceptor with a broad absorption spectrum for organic solar cells. Chem Commun (Camb) 2018;54:303-6. DOI PubMed

77. Lv R, Geng S, Li S, et al. Influences of quinoid structures on stability and photovoltaic performance of nonfullerene acceptors. Sol RRL 2020;4:2000286. DOI

78. Gao H, Sun Y, Cai Y, et al. Achieving both enhanced voltage and current through fine-tuning molecular backbone and morphology control in organic solar cells. Adv Energy Mater 2019;9:1901024. DOI

79. Zhang X, Ding Y, Feng H, et al. Side chain engineering investigation of non-fullerene acceptors for photovoltaic device with efficiency over 15\%. Sci China Chem 2020;63:1799-806. DOI

80. Qian D, Ye L, Zhang M, et al. Design, application, and morphology study of a new photovoltaic polymer with strong aggregation in 
solution state. Macromolecules 2012;45:9611-7. DOI

81. Zhang M, Guo X, Ma W, Ade H, Hou J. A large-bandgap conjugated polymer for versatile photovoltaic applications with high performance. Adv Mater 2015;27:4655-60. DOI PubMed

82. Wu Z, Chen Y, Zhang L, et al. A ligand-free direct heteroarylation approach for benzodithiophenedione-based simple small molecular acceptors toward high efficiency polymer solar cells. J Mater Chem A 2021;9:3314-21. DOI

83. Yu ZP, Liu ZX, Chen FX, et al. Simple non-fused electron acceptors for efficient and stable organic solar cells. Nat Commun 2019;10:2152. DOI PubMed PMC

84. Liu ZX, Yu ZP, Shen Z, et al. Molecular insights of exceptionally photostable electron acceptors for organic photovoltaics. Nat Commun 2021;12:3049. DOI PubMed PMC

85. Wen TJ, Liu ZX, Chen Z, et al. Simple non-fused electron acceptors leading to efficient organic photovoltaics. Angew Chem Int Ed Engl 2021;60:12964-70. DOI PubMed

86. Bao S, Yang H, Fan H, et al. Volatilizable solid additive-assisted treatment enables organic solar cells with efficiency over $18.8 \%$ and fill factor exceeding $80 \%$. Adv Mater 2021. DOI

87. Hong L, Yao H, Wu Z, et al. Eco-compatible solvent-processed organic photovoltaic cells with over 16\% efficiency. Adv Mater 2019;31:e1903441. DOI PubMed

88. Zhou Y, Li M, Lu H, et al. High-efficiency organic solar cells based on a low-cost fully non-fused electron acceptor. Adv Funct Mater 2021;31:2101742. DOI 